\title{
Fats and Spirits: A Story of Modern Humanities' Energy Dependence
}

Tamir, Dan

\begin{abstract}
This chapter examines the relation between the social ability to dedicate time and resources to scholarship in the humanities, and the availability of energy. Its main argument is that the blooming of the humanities during the 19th and 20th centuries was tightly related to the great abundance of cheap fossil fuels - coal, gas, and, most significantly, petroleum - which sparked 'growth' in many aspects of human life, the humanities included. The humanities represent a human occupation which is not aimed at immediate gains or the satisfaction of the most basic needs; therefore, they have been among the first to suffer due to the declining availability of cheap and easy-to-get energy during the past decades. Dwindling resources and threats brought upon by greenhouse gas emissions are now putting an end to the modern flourishing of the humanities, which will need social, economic, and political supporting mechanisms different from those which have been supporting them for the past two centuries.
\end{abstract}

DOI: https://doi.org/10.1007/978-3-030-57480-2_3

Posted at the Zurich Open Repository and Archive, University of Zurich

ZORA URL: https://doi.org/10.5167/uzh-193925

Book Section

Accepted Version

Originally published at:

Tamir, Dan (2021). Fats and Spirits: A Story of Modern Humanities' Energy Dependence. In: Mišík, Matúš; Kujundzic, Nada. Energy Humanities : Current State and Future Directions. Cham: Springer, 37-51.

DOI: https://doi.org/10.1007/978-3-030-57480-2_3 


\title{
Chapter 3
}

Fats and Spirits: A Story of Modern Humanities’ Energy Dependence

\author{
Dan Tamïr ${ }^{1}$
}

\begin{abstract}
While warnings about a crisis in the humanities have often been heard in the past two decades, little attention has hitherto been given to the connection between the current situation in the humanities and the energetic regime allowing their pursuit. This chapter examines the relation between the social ability to dedicate time and resources to scholarship in the humanities, and the availability of energy. Its main argument is that the blooming of the humanities during the 19th and 20th centuries was tightly related to the great abundance of cheap fossil fuels - coal, gas, and, most significantly, petroleum - which sparked 'growth' in many aspects of human life, the humanities included. The humanities represent a human occupation which is not aimed at immediate gains or the satisfaction of the most basic needs; therefore, they have been among the first to suffer due to the declining availability of cheap and easy-to-get energy in the past decades. Dwindling resources and threats brought upon by greenhouse gas emissions are now putting an end to the modern flourishing of the humanities, which will need social, economic, and political supporting mechanisms different from those which have been supporting them for the past two centuries.
\end{abstract}

Keywords Economic growth; Scholarship; Industrial Revolution; Fossil fuels; Petroleum; Peak oil; Dependence

\subsection{Introduction}

The widespread idea of a crisis in the humanities - and in scholarship and non-technical knowledge in general - is hardly secret. A feeling of a deterioration of the humanities (and, to a lesser extent, the 'soft' social sciences) has been around for decades (see, e.g., Bloom 1987). More recently, declarations about a "Silent Crisis" in the study of the humanities, damaging the basis of liberal democratic modern societies (Nussbaum 2016, p. 2) are loud and clear. Some, however, characterise the current situation in the humanities not as a crisis but rather as "an ongoing set of problems", perceiving it less as an immediate threat and more as a structural phenomenon (Donoghue 2010, p. 1). Either way, a notion of decline and deterioration - culturally and politically - has accompanied those working in and with the humanities for quite a while; while the loudest voices surrounding it seem to stem from that part of North America between Canada and Mexico, the trend - differing in its intensity and

\footnotetext{
${ }^{1}$ Dan Tamïr $(\bowtie)$

University of Zurich

dan.tamir@uzh.ch
} 
form - is not limited to that region. This chapter argues that the current situation in the humanities has an energy aspect, which should not be overlooked.

What are the 'humanities'? The exact definition of the term in its scholarly context is not an easy one, as some small differences exist between its usage in various academic traditions. In English, the Oxford Dictionary defines the humanities as "the subjects of study that are about the way people think and behave, for example literature, language, history and philosophy" (Humanity 2020b). Merriam-Webster reiterates this definition as "the branches of learning - such as philosophy, arts, or languages - that investigate human constructs and concerns", as opposed to "natural processes (as in physics or chemistry) and social relations (as in anthropology or economics)" (Humanity 2020a). In French, the Larousse describes "human sciences" as "disciplines whose object [of research] is the human being and his individual and collective behaviours, in the past and in the present" (Sciences 2020, [n.p.]). Accordingly, in the French-speaking sphere, the differentiation between "natural sciences", "life sciences", "social sciences", and "human sciences" is a common one, even though the borders between the human and the social may be blurred. A similar definition prevails in German, where the Duden defines "Geisteswissenschaft" (literally: the sciences of the spirit) as "the entirety of the sciences whose object is the various fields of [human] culture and intellectual life" (Geisteswissenschaft 2020); the German academy, though, has traditionally merged under this definition also what we today call 'social sciences'.

Altogether, under 'humanities' we can understand the research and the investigation of phenomena conducted, construed, or contrived by humans, as opposed to other animals or forces of nature. It is a human endeavour focused on the inner individual or social self, not the practical production of anything nor immediate gain. These definitions of the humanities, however, have a contemporary twist: in an era when humans influence the fundamentals of an entire planet to the degree of modifying entire ecosystems, changing the Earth's atmosphere and climate, is not everything on our planet an object of human agency? Indeed, our era of allencompassing human influence named the Anthropocene (Crutzen \& Stoermer 2000), might be changing the essence of the humanities, or at least the way we perceive them: if everything in our world is influenced by human action, then everything may be considered as part of the humanities. It is not surprising, therefore, that the field of environmental humanities is gaining ground, encouraging humanists to look at the entire world as relevant to the human experience, and seek the human experience in all parts and aspects of our environment (Holm et al. 2015). As we shall see, however, even the most theoretical and non-material pursuit of the humanities has energetic dependencies; the humanities, in other words, have an energetic history of their own.

However, 'history of the humanities' is not a common token and its study is not as established a field as the history of the natural sciences, to the degree that some assert that the humanities completely "lack a general history" (Bod 2013, p. 1). Such a decisive assertion might sound as a bit of an over-exclamation, but it is true that a 'mainstream', general and agreed upon history of the humanities is not common knowledge. The lack of a general history of the humanities stands in clear contrast with the abundance of modern natural science in various world histories (see, e.g., Bynum 2012; DeWitt 2010; Gribbin 2010): 
whereas a 'history of science' is a common thing, a 'history of the humanities' is hardly existent.

One appealing explanation for the lack in humanities history is the increased fragmentation which has gradually been taking place within the humanities during the past 200 years, a fragmentation which seems as an opposite move to the search for unifying theories guiding the natural sciences, at least as their desired outcome, if not their daily practice (Bod 2013, p. 4). A second explanation or a general reason for this lack may be that hitherto very little research has been conducted on the relationship between the humanities which are usually associated with intellect and spirit - and their physical environment. While the connection between the natural sciences and the surrounding physical environment seems to go without saying, the connection between the humanities and the environment seems less obvious.

This historiographical lack has multiple faces, but a part of it is the lack of a history of the connection between the humans' occupation with the humanities and the physical resources available to them, which enable the mere existence of that pursuit of knowledge. Energy - the basis of our physical existence and activity - is a good place to start filling this gap between spiritual contemplation and physical existence: the 'energy humanities' can be perceived as a field of scholarship that overcomes the boundaries between disciplines, and between academic and applied research, highlighting the essential contribution that the insights and methods of the human sciences can make to areas of study and analysis that were once thought best left to the natural sciences (Boyer \& Szeman 2014).

The aim of this chapter is to draw a very brief description of the relations between energy and the study of the humanities during the past few centuries (a time period marked by a deep schism with its energetic past), sketch an outline for our contemporary humanities-energy nexus and crisis - a crisis made up of a combination of the unwanted consequences of the use of fossil fuels and the dwindling of some of them - and finally suggest some foundations for a future agenda for the humanities, based on the threats our current energetic situation poses and the opportunities it creates. This chapter takes a point of view not from the humanities towards energy, but rather from energy towards the humanities: it first provides a short review of humanity's longue durée energetic history, focusing on the shift from the old regime to the new one. After defining and analysing the significance of the different phases in the development of the new energy regime, it shows how that material energetic development enabled and shaped the development of the humanities in academia during the past two decades. It then suggests that the current crisis in the exploitation of fossil fuels is now once again reshaping academia in general and the humanities in particular (partially taking these back to the place they had before the era of fossils). Finally, the chapter portrays a possible vision of a future for the humanities, based on the current global energy situation and the world's predicted energetic future.

\subsection{Energy and Human Endeavour}


Like any human activity, research and teaching are bound to various forces influencing and shaping human societies. These forces are social, political, ideological - and material. Thus, depending and relying on ideas, innovation, cognition, and spiritual and mental efforts as she may be, academia still requires material infrastructure and resources in order to sustain herself. While the joke about the history professor who needs nothing but books and a computer, and the philosophy professor who does not even need a computer is an exaggeration, it is true that the material demands of the humanities are considerably lower compared with those of the natural sciences, which require laboratories, consumable materials, large spaces, machinery, and further infrastructure. However, pursuing the humanities still requires a certain amount of real, tangible matter. This includes not only books, journal subscriptions, access to archives, computers, pencils, desks, and travel mechanisms, but the entire complex system which allows people to engage in and devote themselves to scholarly work which does not yield immediate results or gains. Even ascetic philosophers and extreme theoreticians must eat something every now and then, and keep their studios, rooms, and offices warm during cold winter nights. In short: they are humans and everything they do requires energy.

Like all other living creatures, humans rely on external energy sources in order to exist and act. Furthermore, as social animals, humans do not act only as individuals: this means that all human societies can therefore be seen as systems aimed at collecting energy available from various sources, processing and re-distributing it through various social mechanisms which may describe society. The amount and kind of energy available to a society are two factors which define the framework within which social processes can take place. Therefore, the analysis of historical energy flows provides an explanation - not a unique or single explanation, but still a valid one - for the basic patterns of different social formations and actions (Crosby 2006).

\subsection{Different 'energy regimes'}

The energy history of humanity may be divided roughly into two eras, based on two energetic regimes: the 'old regime' and the 'new regime'. The 'old regime' is based on the annually renewable energy deriving from the sun, from direct radiation to subsidiary kinds of energy, such as wind, the flow of rivers, and the organic material accumulated in plants during the process of photosynthesis, which is possible thanks to sunlight. The 'old' regime was - and still is, in many parts of the world - based on the annual radiation of the sun, giving modest energetic gains for every action made by humans and allowing only little accumulation of energy and wealth in both time and space.

The 'new regime' also involves fossil fuels (Burke 2009; Sieferle 2001, pp. 4-34). While the temporal distinction between the two is not clear-cut (they still co-exist in various parts of the world), the 'new regime' is actually defining the modern world as the basis for our contemporary modern industrial civilization. Nuclear energy is another feature of the new regime, whereas energy from renewable sources is additional to the fossils, not their replacement (a total replacement of fossils by renewable sources in the future may signal the 
beginning of a new era). The new regime can be further subdivided in accordance with the three main fossil fuels humans use: coal, gas, and petroleum.

Energy is absolutely necessary not only to modern societies (Szeman \& Boyer 2017), but to any society, be it modern or not. However, without the forms and quantities of energy to which we have access and which we now take for granted, industrialisation and modernity would never had existed: the modern (and Northern-dominated) world came to be what it is today thanks to the broad and intensive use of fossil energy. As part of the entire human endeavour, the development of the humanities during the past two centuries is tightly bound with the technical achievements of the new energy regime during that same period. In the 19th century, modern societies moved from using human and animal labour to using fossil fuels. This transition was what made them industrial and modern.

This energetic development was not straightforward, and included several phases, generally parallel to the finding, adoption, and implementation of new fossil fuels: from the beginning of the use of coal during the early $19^{\text {th }}$ century, through the switch from coal to petroleum, and to the great acceleration of the 1950s - the rapid increase in the growth of every material aspect of human life, from food to transportation and from textile manufacture to radio programmes, also known as the '1950s Syndrome' - due to new oil discoveries and improved extraction and combustion technologies (Crosby 2006; Pfister 1996; Steffen et al. 2015). Like other intellectual occupations, the humanities were also part of this, as these phases are parallel to the blooming of new universities and faculties, the establishment of the Geisteswissenschaften, and then the 'boom' in higher education in the industrialised world as well as the crisis we are witnessing today.

\subsubsection{Modern Times: Coal Makes the 'New Regime'}

Three main fossil fuels are used today. Whereas the broad commercial use of gas began (in historical terms) just recently, petroleum was available from the late 19th century (Heinberg 2003; Smil 2006). However, it was coal, in broad use from the 18th century, which enabled the "Great Departure" from an old-world order to a new one (Marks 2007, pp. 189-194). That shift from renewable solar-cycle energy to fossil energy accumulated in coal had a deep and wide influence on all parts and aspects of human life, from the micro daily schedule and habits of individuals to the macro political history of the world in the modern era.

The introduction of coal into human economies had both an immediate, practical, and quantitative effect and a qualitative, conceptual one. Quantitatively, the past two centuries stood in the sign of plenty, richness, and an ongoing expectation of material abundance. It is worthwhile pausing for a moment to grasp and comprehend the huge difference between the amount of energy currently available to the average citizen in modern industrialised society and the amount of energy that was available to his/her ancestors about eight generations ago, in the early 19th century. The amount of energy available to the average human today is twice as big as the amount of energy that was available to his/her grandparents 60 years ago and about four times the amount of energy available to their grandparents (Smil 2017). One outcome of the substitution of human labour with machines was the liberation of a constantly 
growing percent of the population in industrial societies from their age-old work in the production of food and goods, allowing a growing part of the population to take part in activities other than supplying basic needs - such as reading, writing, and studying. Qualitatively, the main conceptual effect induced by that energetic transition was 'growth': the notion that individuals, societies, and even humanity in general are bound to have more and more available material and energy with every passing period of time.

Altogether, the essence of the coal-based Industrial Revolution was equipping each worker with more energy and capital, thus increasing production and the average income of the entire population. Soon, people began to expect to be better paid and enjoy the benefits of leisure and consumption allowed by the new energy regime (Kander et al. 2013, p. 158). It is exactly this leisure that made the widening of the humanities possible; this widening became even greater with the mass usage of petroleum.

\subsubsection{The 20th Century: Oil Makes the World Go Round}

Although their chemical and natural origins are similar, oil has several operational advantages over coal and gas. First, unlike coal, which needs to be lifted and shovelled, oil is less bulky, and can be transported and delivered by tanks, barrels, or small pipelines. It therefore requires less manpower for extraction, shipping, distribution, and delivery. Oil used to be relatively easily extracted: during the booming years of cheap, accessible oil, the drilling of oil wells, the shipping of crude oil, and its final refining demanded a very small investment of energy and a few workers compared to the inputs required to operate coal mines. Second, it is relatively stable: unlike gas, which has to be well sealed in closed containers, cooled down or liquified, oil is not likely to diffuse or evaporate when kept in a wide range of temperatures. Last but not least, oil can be quite easily processed into a variety of different products: from gasoline to plastic toys, from lubricants to fertilizers. Cheap, flexible, and abundant, it endowed modern industrial societies with an immense quantity of readily available energy.

With these features well established, no wonder that engines fuelled by petroleum products became the movers of the 20th century's global society (Smil 2010, p. 216). Of course, oil is only one energy source out of many and should not be the only prism of our energy research (Jones 2016). Yet today, oil presents society with a large portfolio of problems: rapid global warming; serious, world-altering globalised environmental crises related to its extraction; increasing geopolitical instability and armed conflicts related to control of oil supplies; and, finally, a possibly imminent failure of supply that would deeply affect the world's economic and social systems. Oil has become essential to all aspects of humans' way of life, from agriculture and healthcare to transportation and consumer goods (Buell 2012; Heinberg 2003): these are the social systems and infrastructures which support the pursuit of all scholarship - including the humanities.

And how cheap oil was and still is! A common way of pricing energy - and many other things - is in invented money: GBP per unit of gas or USD per barrel of oil. Modern currencies, however, are a human imaginary invention; the real price of energy is the energetic cost of extracting it: how many units of energy one has to invest in order to extract 
another unit of energy. This is referred to as the Energy Return on Investment, or EROI. For example, investing 10 calories in a process which grants us 20 calories reflects an EROI of $1: 2$; investing the energy equivalent of 100 apples in order to get the energy equivalent of 1,000 apples gives an EROI rate of 1:10.

Measured in EROI, petroleum was an energetic bonanza: at the beginning of the 20th century, the estimated EROI for petroleum was around 1:100. This ratio declined with time but was still very profitable during most of that century: in some oil fields during the 1960 s, the energetic return was still around 40. This means that for every unit of energy invested in drilling, pumping, distilling, and shipping, 40 units of energy were delivered (Murphy \& Hall 2010). From the end of the 19th to the beginning of the 21 st century, thanks to discoveries of new oil fields and improving drilling techniques, petroleum was available in ever-growing quantities. Even if the net return on investment was steadily decreasing, the total amount of oil extracted continued to grow. This steady growth in energetic inputs easily inspired two economic thoughts: first, that 'growth' is and should be an integral part of modern economy; second, that this growth can continue on and on (Heinberg 2003).

\subsubsection{Growth and Its Limits}

The sudden availability of fossil fuels - with oil being of central importance among them and their growing annual rates of extraction during the 20th century have laid the ground for a new social and economic order which has - as far as we can tell - no historical precedence. That order is based on and aimed at 'growth'; although it is usually referred to as economic growth, it actually encompasses all parts of life. Supported by the increasing availability of energy inputs during the 20th century, growth became the political belief of the late 20th century. Although in different facets and within different political contexts, the belief that human consumption, population size, and available services can 'grow' was shared by both capitalist and communist societies, liberals and social-democrats - to the degree that some scholars claim that within the Anthropocene, our era is the era of growth or the Auxocene (Reichel \& Perey 2018). The disputes between different political parties and factions were and to a large extent, as long as mainstream political camps stay bound to anachronistic paradigms, still are - merely about the distribution of accumulated wealth and the way the pieces of the growing pie should be divided. All believed that the pie was growing and would continue to grow.

When viewed through the narrow prism of the second half of the 20th century, the global economy seemed to be growing: every year more oil was extracted and more energy was available to humanity. The availability of cheap, abundant fossil fuels was the main force driving the economic growth since the beginning of the 20th century, especially from the 1950s onwards (Pfister 1996): more available energy meant more food, more people, more commodities, more mobility, more of everything manufactured or invented by people, as a matter of fact (and less of everything else, from rainforests to fish in the sea). However, like coal and gas, petroleum is a limited, non-renewable resource, which is about to be depleted 
after reaching a 'peak' in its extraction (Campbell \& Laherrère 1998; Heinberg 2006; Hirsch 2005). And indeed, it is depleting (Chapman 2014; Murray \& King 2012).

Soon, however, this increased economic activity caused by the growing availability of energy raised considerable criticism and scepticism. During the early 1970s, Nicholas Georgescu-Roegen $(1971 ; 1977)$ already pointed out that the material limits of the world in which humans live do hinder, by definition, future economic growth: infinite consumption and growth are impossible in a finite world, without external inputs. Therefore, he concluded, growth will have to end, sooner or later. The best publicly known expression of the initial fear of exhausting that 'growth' was probably the one articulated by the 'Club of Rome' - a group of natural and social scientists, named after the city in which it first congregated - which doubted the entire ability of humanity to sustain its economic growth, due to employment insecurity, environmental degradation, monetary disruptions, rapid changes in traditions, and the breaking of social institutions (Meadows et al. 1972). All of these reports and critics of the ruling financial order emphasised our inability to continue growing infinitely in a finite world. The mainstream media and most of the world's governments will not admit it, because it is 'bad news' for our consumer society; but by the beginning of the 21 st century, the futility of the attempts to sustain the unsustainable has become clear (Seidl \& Zahrnt 2010).

\subsection{Humanities and Energy Shifts}

Doubtful by their nature as they are and disliked as they ought to be, generalisations are not always bad; in the case of the old energetic regime and its influence on the humanities, they may even be useful. The humanities have their history of continuity and change, through which they neither stood still nor stayed frozen in any way: from their beginnings in the ancient world, through classical and medieval eras, in various places and various social, religious, and political constellations, the humanities changed deeply in their methods, foci, and social acceptance, to name just a few characteristics of their place in the history of knowledge and ideas (Bod 2013).

That being said, the humanities were also part of the energetic surroundings of humanity, as mentioned above: societies' ability to allow their members to engage in activities that are not related to immediate needs is dependent on the amount of 'spare' energy available to them. The division between an old and a new energy regime is valid here as well. For the purpose of our discussion, here we can assume that the ancient and medieval history of the humanities saw relatively small and very slow changes during the period until the early modern era: enriching humans' knowledge about the world and themselves had to do more with preserving old than creating new knowledge. In societies which relied on human labour and muscle energy for catering to basic needs (mostly food supply), only a tiny percentage of the population could engage itself fully with occupations which were not directly related to physical work and labour. In the times before the usage of fossil fuels, farmers, masons, herders, foresters, and artisans were all needed in large numbers. Only a small percentage of the population could evade the physical toil and engage in the work of the brain and not of the body. The Roman admiration for vita contemplativa - as opposed to vita activa - was all but an expression of that desire: probably shared by many but accomplished only by few. 
Accordingly, the engagement with the humanities was limited and small in numbers. This is, of course, not to say that past cultures were less developed or lacked some qualities that modern societies have, or that ancient and medieval humanities were of lower grade, but that the social reach of the humanities, as a distinct faculty of human life, was limited.

The new energy regime brought a deep change to the history of the humanities. With their qualitative essence and role in human societies well established, changes in the humanities at the early stages of the new regime, during the 19th century, were structural and institutional rather than essential or qualitative. They included specialisation and professionalisation, the creation of local and national - rather than universal - foundations for research in the humanities, and finally the separation from the natural sciences. Most distinctively, new in the 19th century was the academic institutionalisation of disciplines, not so much the nature of humanistic knowledge as a whole (Bod et al. 2014).

While the early roots of the aforementioned processes may be traced to the 18th century, the later rise of modern industrial civilization accelerated them considerably. One of the earliest and most commonly cited expressions portraying the specialisation of the humanities is the one coined by Charles P. Snow, who refers to the humanities and the natural sciences as 'two cultures', with a substantial gap between them $(1956 ; 1959)$. Another chasm portrayed in Snow's book (1959) received less attention during the past decades. This is the gap which developed between the humanities (and theoretical scientists to some degree) and modern technology. "If we forget the scientific culture", Snow opines, "then the rest of western intellectuals have never tried, wanted or been able to understand the industrial revolution, much less accept it" $(1959$, p. 23). As a matter of fact, Snow argues, academics had nothing to do with the Industrial Revolution, for "so far as there was any thinking in nineteenth-century industry, it was left to cranks and clever workmen" - not to academics and certainly not to humanists (ibid., p. 25). The latter practically 'survived' through one of the greatest transformations humanity had ever seen (second maybe only to the agricultural revolutions millennia earlier), while benefiting from its amenities.

Today, when the decreasing returns on energy investments bring the age of expansion and prosperity to its end, the humanities will no longer be able to join the ride and enjoy the plenitude as it used to during the past century. The evidence is already clear: during the past several decades, and increasingly since the 1980 s, higher education became an industry to itself, as academic degrees and publications became a commodity or consumer goods, produced in growing quantities with no direct purpose except the continued operation of the institutions and mechanisms producing them. Now, with global growth decreasing or disappearing altogether, it cannot continue growing and expanding. The production of education in masses unknown before - a large part thereof in the humanities - cannot be sustained as it is based on borrowing and debts meant to be 'paid off' sometime in the future. The sheer joy of the humanities is a great thing; alas, it does not pay off in any practical way in the material world, whose margins are once again becoming narrower.

The United States of America provide an extreme yet telling example with regard to the phenomenon in general. During the first half of 2019, the debts of 44 million current and former students in the U.S. alone were estimated around 1.5 trillion USD, making every U.S. 
university graduate begin his/her early-career life with a debt of around 35,000 USD on average (Friedman 2019). Students with a strong economic background probably owe much less; one may therefore assume that many former students carry much bigger loans they have to pay. Indeed, about 11\% (around 166 billion USD) of these debts are in some kind of service failure (Tanzi 2019). Nowadays, some college students actually go hungry in order to pay their tuition fees and other living expenses (Laterman 2019). Other countries may be presenting less staggering figures, but the tendency is similar worldwide; in the European Union, student debt may be public rather than private but is debt all the same. Can this situation continue as it is, given the fact that the resources available to sustain our modern society are dwindling?

\subsection{Discussion and Conclusion: What next?}

Humanity has entered an age of crisis, and our only way out is to think more deeply about the global connections between politics and ecology. Human history has always been part of all the other lives on Earth and there is no way for us to escape from that common fate (Hou 2018). The humanities are not dissociated from human lives, so this applies to the humanities as well: engaging in the humanities means freedom from catering for one's basic needs and most of our freedoms so far have been energy-intensive, from the time of the early civilisations on Earth (Chakrabarty 2009). The more energy provided, the more freedom humans enjoyed; in our case, the free scholar who has someone or something else take care of his/her supply of material. What should we expect now, when the amount of energy available to us is not growing anymore? Should we expect less freedom and hence a lower ability to engage ourselves in the humanities, now that the 'new' energy regime is about to go into a deep change?

Problematically, the current public discourse and debates on energy tend to approach fossil fuels as a problem of greenhouse gas (GHG) emissions, with its direct impact on climate change and all the calamities that derive from it. Indeed, GHG emissions are a dire problem and an immediate threat to us all. However, 'the problem' of fossil fuels is much more than climate change and should not be limited to emissions or pollution. When we look at it on a wide scope, climate change is but one symptom of a larger systemic problem of the global political economy of extraction and combustion (Princen et al. 2015, pp. 5-6). Fossil fuels have deeply changed human society in every possible aspect and in every field of life: our food, our mobility, our ability to produce and consume goods, our time management, our spatial perception, our health and life expectancy, our social interactions and family relations, our education systems and political structures, our communication, our span of attention, and even our imagination. In short: it changed our life. And it is not sustainable - or even durable - in any way. It will have to come to an end.

What can we do with this? Where can we take the humanities to now, from the dire energy straits in which they are, together with the rest of humanity's modern endeavour? In order to find some reasonable answers to these questions, we first have to distinguish between four related yet distinct issues. It may well be that at least part of the confusion we are 
experiencing and the feeling of anxiety and lack of orientation prevalent among humanists (as well as others) is due to the confusion between these issues. The first issue is defining and acknowledging the problem of modern scholarship - the humanities included - in relation to energy resources. The second issue is admitting what is not likely to happen and what is not reasonable to expect. The third issue - standing in contradiction to the second - is what may be possible to achieve. The fourth issue is what is desired and what we wish for, under the given conditions. While the first three issues are positivist by nature - even if not precise, and subject to different assessments and interpretations - the last one is normative.

First, the root of the problem of modern scholarship in general and the humanities in particular in relation to energy resources is basically the problem facing the entire modern civilisation: the declining availability of easy-to-get, accessible energy. The combination of a growing population and the diminishing returns on energetic investments led us all to a situation in which more and more people have to share a pie which is not growing anymore and may soon be shrinking. This is even before we begin to deal with the environmental damages caused by the burning of fossil fuels and the socio-political havoc these are already causing through climate change and the mass destruction of habitats and livelihoods (Princen 2014; Tollefson 2016). One more thing we must remember in this context is that clean energy from renewable sources is not likely to fill the gap between current energy demand and future energy supply. We currently have no technology that would sufficiently substitute fossil fuels in all their usages and in the quantities currently combusted.

Therefore, some things are not likely to happen and are not reasonable to expect. Foremost among these is the flawless continuation of the 20th century's norm of drilling, pumping, and burning, while creating an imagined and unsustainable 'growth' on the one hand and turning the Earth's atmosphere into a huge greenhouse on the other. This 'business as usual' situation is likely to stop sooner or later both because of the environmental damages it causes and because of the exhaustion of the reserves of petroleum, the main resource enabling it (although one should not hope for the latter to stop the former, as there are still enough fossils to be burned in order to destroy our biosphere three times over; Princen 2014). As a consequence, we may suspect that processes which have become a norm during the fossil fuel era - growth, specialisation, centralisation - will also come to a halt. Nonetheless, given the scientific and technological knowledge accumulated, tested, and implemented during the past centuries, we may well assume that we are not going back to the Stone Age or the 'Olduvai Gorge' (Duncan 2007): humanity has made enough technological progress from the Stone Age to early modern times and complex societies have existed for millennia without fossil fuels. Dystopian visions of our modern global human society dismembering into thousands of detached, naked cave-dwelling tribes of nomads provide the base for an interesting literary experience but will probably prove to be exaggerated in reality.

What might be possible to achieve, therefore, is a new social, political, and economic order (in this case all three words are synonyms), which will not be based on growth and will not take growth as one of its components. The transition to such a new order will require a rearrangement of all aspects of our lives, a re-planning, descaling, and probably decentralising of our current institutions. History does not repeat itself, but it may rhyme: we do have 
historical precedents and examples of societies which survived, thrived, and even flourished without economic growth. Growth is a new phenomenon, and although the forces that try to make us forget the past (or at least blur it) are considerably strong, it is not beyond our capacity to look back into history and find plenty of examples and lessons. As a matter of fact, all pre-industrial economies lived in a relatively steady situation, with no or only negligible growth. To achieve this, we shall definitely need the humanities (history, literature, linguistics, archaeology): to look into our pre-industrial history as humans and imagine a postindustrial society. Looking at our human ancestors may teach us how can we live without fossil fuels, while using our imagination and language skills may assist us in inventing new, updated, and suitable systems and tools for living like that anew in the future.

What future exactly? The answer to this question is not positivist but rather normative. It is not the question of what we can, but of what we want and desire. After finding and learning a set (or a spectrum) of possibilities, we will have to redraw the outlines of a new global human society, based on renewable energy sources. The reorganisation of our lives will demand a deep and thorough redistribution of wealth and labour, as well as changes in occupations, family ties, and political regimes. Do we want higher or lower inequality? Do we want more openness or more seclusion? Do we wish for more connections or would we prefer breaking into more isolated social units? Whether we define the current situation within the humanities as a crisis or as a set of problems (Donoghue 2010; Nussbaum 2016), the humanities themselves - like all other parts of life and society - will have to break from the frames and the institutions to which they were bound during the industrial era.

The good news, however, is that the humanities - while having to reorganize and adapt to an era of relative scarcity and decrease - may help us make wise decisions. The current energetic predicament of modern society is made of natural factors - resources and emissions - but is entirely human-made. Both at its extraction end, with declining returns from our current energy sources, and at its emission end, with pollution and climate change threatening billions of people around the world, our modern energy economy was and still is planned, built, and maintained by humans. As our entire economy, our current energy regime is based neither on divine ruling nor some natural law; it is a social construct. Therefore, it is up to us, humans, to change and improve it, or - as seems to be the case here - abandon it and develop a new one to replace it. A primary precondition for good decision making is a clear view of reality. Studying, mapping, and analysing human ideas, thoughts and actions is exactly the mandate of the humanities. Energy humanities, then, can and should play a central role in learning from our past human experience, analysing our present human situation, and envisioning a novel energy regime in which humans may think and act in the future.

\section{Bibliography}

Bloom, A. (1987). The Closing of the American Mind: How Higher Education Has Failed Democracy and Impoverished the Souls of Today's Students. New York: Simon \& Schuster.

Bod, R. (2013). A New History of the Humanities. New York: Oxford University Press. 
Bod, R., Maat, J., \& Weststeijn, T. (2014). Introduction: The Making of the Modern Humanities. In R. Bod, J. Maat, \& T. Weststeijn (Eds.), The Making of the Humanities. Volume III: The Modern Humanities (pp. 13-24). Amsterdam: Amsterdam University Press.

Boyer, D., \& Szeman, I. (2014). The rise of energy humanities. University Affairs. https://www.universityaffairs.ca/opinion/in-my-opinion/the-rise-of-energy-humanities/. Accessed 5 March 2020.

Buell, F. (2012). A Short History of Oil Cultures: Or, the Marriage of Catastrophe and Exuberance. Journal of American Studies, 46(2), 273-293. doi:10.1017/s0021875812000102.

Burke, E. (2009). The Big Story: Human History, Energy Regimes, and the Environment. In E. Burke III, \& K. Pomeranz (Eds.), The Environment and World History (pp. 33-53). Berkeley \& Los Angeles: University of California Press.

Bynum, W. (2012). A Little History of Science. New Haven: Yale University Press.

Campbell, C., \& Laherrère, J. (1998). The End of Cheap Oil. Scientific American, 278(3), 7883. doi:10.1038/scientificamerican0398-78.

Chakrabarty, D. (2009). The Climate of History: Four Theses. Critical Enquiry, 35(2), $197-$ 222. doi:10.1086/596640.

Chapman, I. (2014). The end of Peak Oil? Why this topic is still relevant despite recent denials. Energy Policy, 64, 93-101. doi:10.1016/j.enpol.2013.05.010.

Crosby, A. (2006). Children of the Sun: A History of Humanity's Unappeasable Appetite for Energy. New York: Norton.

Crutzen, P., \& Stoermer, E. (2000). The Anthropocene. Global Change Newsletter, 41, 17-18.

DeWitt, R. (2010). Worldviews: An Introduction to the History and Philosophy of Science. Malden: Wiley-Blackwell.

Donoghue, F. (2010). The Last Professors: The Corporate University and the Fate of the Humanities. New York: Fordham University Press.

Duncan, R. C. (2007). The Olduvai Theory: Terminal Decline Imminent. The Social Contract, $17,141-151$.

Friedman, Z. (2019). Student Loan Debt Statistics in 2019: A \$1.5 Trillion Crisis. Forbes. https://www.forbes.com/sites/zackfriedman/2019/02/25/student-loan-debt-statistics-2019/ \#3c170178133f. Accessed 25 February 2019.

Geisteswissenschaft.

(2020).

Duden. https://www.duden.de/rechtschreibung/Geisteswissenschaft. Accessed 11 March 2020.

Georgescu-Roegen, N. (1971). The Entropy Law and the Economic Process. Cambridge, MA: Harvard University Press. 
Georgescu-Roegen, N. (1977). The Steady State and Ecological Salvation: A Thermodynamic Analysis. BioScience, 27(4), 266-271. doi:10.2307/1297702.

Gribbin, J. (2010). Science: A History. London: Penguin Books.

Heinberg, R. (2003). The Party's Over: Oil, War and the Fate of Industrial Societies. Gabriola Island: New Society Publishers.

Heinberg, R. (2006). The Oil Depletion Protocol. Gabriola Island: New Society Publishers.

Hirsch, R. (2005). The Inevitable Peaking of World Oil Production. Atlantic Council Bulletin, 16(3), 1-9.

Holm, P., Adamson, J., Huang, H., Kirdan, L., Kitch, S., McCalman, I., Ogude, J., Ronan, M., Scott, D., Thompson, K. O., Travis, C., \& Wehner, K. (2015). Humanities for the Environment - A Manifesto for Research and Action. Humanities, 4(4), 977-992. doi:10.3390/h4040977.

Hou, S. (2018). Wanted: A Planetary History for an Age of Crisis. Environmental History, 23(1), 152-156. doi:10.1093/envhis/emx130.

Humanity.

(2020a).

Merriam-Webster. https://www.merriam-webster.com/dictionary/humanities. Accessed 11 March 2020.

Humanity. (2020b). Oxford Learners' Dictionary. https://www.oxfordlearnersdictionaries.com/definition/english/humanity?q=humanities. Accessed 11 March 2020.

Jones, C. F. (2016). Petromyopia: Oil and the Energy Humanities. Humanities 5(2), 36. doi:10.3390/h5020036.

Kander, A., Malanima, P., \& Warde, P. (2013). Power to the People: Energy in Europe over the Last Five Centuries. Princeton: Princeton University Press.

Laterman, K. (2019). Tuition or Dinner? Nearly Half of College Students Surveyed in a New Report Are Going Hungry. New York Times. https://www.nytimes.com/2019/05/02/nyregion/hunger-college-food-insecurity.html. Accessed 2 May 2019.

Marks, R. (2007). The Origins of the Modern World: Fate and Fortune in the Rise of the West. Lanham: Rowman and Littlefield.

Meadows, D. H., Meadows, D. L., Randers, J., \& Behrens III, W. W. (1972). The Limits to Growth. A Report for the Club of Rome's Project on the Predicament of Mankind. New York: Universe Books.

Murphy, D. J., \& Hall, C. A. S. (2010). Year in review - EROI or energy return on (energy) invested. Annals of the New York Academy of Sciences, 1185(1), 102-118. doi:10.1111/j.1749-6632.2009.05282.x. 
Murray, J., \& King, D. (2012). Oil's tipping point has passed. Nature, 481, 433-435. doi:10.1038/481433a.

Nussbaum, M. (2016). Not for Profit: Why Democracy Needs the Humanities. Princeton: Princeton University Press.

Pfister, C. (1996). Das "1950er Syndroms": Die umweltgeschichtliche Epochenschwelle zwischen Industriegesellschaft und Konsumgesellschaft. In C. Pfister (Ed.), Das 1950er Syndrom: Der Weg in die Konsumgesellschaft (pp. 51-95). Bern: Haupt.

Princen, T. (2014). The Politics of Urgent Transition. In Y. Wolinsky-Nahmias (Ed.), Changing Climate Politics: U.S. Policies and Civic Action (pp. 218-238). Thousand Oaks, CA: Sage.

Princen, T., Manno, J., \& Martin, P. (2015). The Problem. In M. Princen, \& J. Martin (Eds.), Ending the Fossil Fuel Era (pp. 3-36). Cambridge, MA: MIT Press.

Reichel, A., \& Perey, R. (2018). Moving beyond growth in the Anthropocene. The Anthropocene Review, 5(3), 242-249. doi:10.1177/2053019618799104.

Sciences.

Larousse.

https://www.larousse.fr/dictionnaires/francais/sciences/71468/locution?q=

\%22sciences+humaines\%22\#174927. Accessed 11 March 2020.

Seidl, I., \& Zahrnt, A. (2010). Argumente für einen Abschied vom Paradigma des Wirtschaftswachstums. In I. Seidl, \& A. Zahrnt (Eds.), Postwachstumsgesellschaft: Konzepte für die Zukunft (pp. 23-36). Marburg: Metropolis Verlag.

Sieferle, R. (2001). The Subterranean Forest: Energy Systems and the Industrial Revolution. Cambridge: White Horse Press.

Smil, V. (2006). Transforming the 20th Century: Technical Innovations and their Consequences. New York: Oxford University Press.

Smil, V. (2010). Prime Movers of Globalization: The History and Impact of Diesel Engines and Gas Turbines. Cambridge, MA: MIT Press.

Smil, V. (2017). Energy and Civilization: A History. Cambridge, MA: MIT Press.

Snow, C. P. (1956). The Two Cultures. The New Statesman, 52(1334), 413-414.

Snow, C. P. (1959). The Two Cultures and the Scientific Revolution. New York: Cambridge University Press.

Steffen, W., Broadgate, W., Deutsch, L., Gaffney, O., \& Ludwig, C. (2015). The Trajectory of the Anthropocene: The Great Acceleration. The Anthropocene Review, 2(1), 81-98. doi:10.1177/2053019614564785.

Szeman, I., \& Boyer, D. (2017). Introduction: On the Energy Humanities. In: I. Szeman, \& D. Boyer (Eds.), Energy Humanities: An Anthology (pp. 1-14). Baltimore: Johns Hopkins University Press. 
Tanzi, A. (2019). U.S. Student Debt in 'Serious Delinquency' Tops \$166 Billion. Bloomberg. https://www.bloomberg.com/news/articles/2019-02-16/u-s-student-debt-in-seriousdelinquency-tops-166-billion. Accessed 16 February 2019.

Tollefson, J. (2016). 2015 breaks heat record: Pacific Ocean warming helped make last year the hottest in history. Nature, 529(7587), 450. 